\title{
Snow melting bias in microwave mapping of Antarctic snow accumulation
}

\author{
O. Magand, G. Picard, L. Brucker, M. Fily, and C. Genthon \\ Laboratoire de Glaciologie et Géophysique de l'Environnement, CNRS, Université Joseph Fourier-Grenoble, 54 Rue Molière, \\ BP 96, 38402 St Martin d'Hères Cedex, France
}

Received: 13 February 2008 - Published in The Cryosphere Discuss.: 24 April 2008

Revised: 29 August 2008 - Accepted: 29 August 2008 - Published: 12 September 2008

\begin{abstract}
Satellite records of microwave surface emission have been used to interpolate in-situ observations of Antarctic surface mass balance (SMB) and build continental-scale maps of accumulation. Using a carefully screened subset of SMB measurements in the $90^{\circ}-180^{\circ} \mathrm{E}$ sector, we show a reasonable agreement with microwave-based accumulation map in the dry-snow regions, but large discrepancies in the coastal regions where melt occurs during summer. Using an emission microwave model, we explain the failure of microwave sensors to retrieve SMB by the presence of layers created by melt/refreeze cycles. We conclude that regions potentially affected by melting should be masked-out in microwave-based interpolation schemes.
\end{abstract}

\section{Introduction}

Arthern et al., 2006 have recently produced a new Antarctic Surface Mass Balance (SMB) map (referred as A06) using both field measurements and microwave and thermal infrared remote sensing data. The same SMB measurements as in the former SMB map (Vaughan et al., 1999) (referred as V99) are used, but a new geostatistical method is applied to interpolate the ground measurements to every point of the gridded map. The interpolation relies on a spatial background model of the accumulation based on the annual-mean thermal infrared temperature and the polarisation ratio of microwave brightness temperature at $4.3 \mathrm{~cm}$ wavelength $(6.9 \mathrm{GHz})$. Microwave brightness temperature has been shown to be a good proxy of SMB in Greenland (Winebrenner et al., 2001) and in Antarctica (Vaughan et al., 1999). These former studies used however a shorter wavelength $(0.8 \mathrm{~cm}$, i.e. $37 \mathrm{GHz})$ which is more sensitive to snow grain scattering and consequently

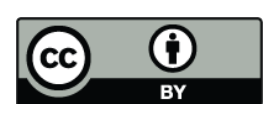

Correspondence to: G. Picard (ghislain.picard@lgge.obs.ujfgrenoble.fr) is more dependent on grain size. According to A06, the new map describes the average SMB with an accuracy of $10 \%$ or better at an effective spatial resolution of $100 \mathrm{~km}$. The authors also suggest the new SMB map may eliminate some of the discrepancies between climate models and earlier compilations or maps of SMB as observed by (Genthon and Krinner, 2001).

The microwave energy emitted (relevant for passive measurements) or backscattered (relevant for active measurements) by dry snow pack is sensitive to the number of layers (characterized by a jump in density inducing a jump in refractive index) over a given depth. In addition, the number of layers seems related to the annual snowfall accumulation over ice sheet. These two facts are the foundation of using the polarisation ratio (Arthern et al., 2006) as well as of using active instruments to map the SMB distribution in Greenland, including scatterometer (Drinkwater et al., 2001) and Synthetic Aperture Radar (Forster et al., 199; Munk et al., 2003). However, snow accumulation is not the only factor influencing the morphological structure of the snow pack. Pronounced density contrasts within the snow pack may also result from ice layers and/or ice lenses created by refreezing of melt-water. Refreezing can occur at some depth in the cold snow pack while melt-water may be produced at the surface, usually during summer, in coastal areas and at the surface of ice shelves (Van den Broeke et al., 2006). The contribution of melting to the internal layering in the snow pack implies a) that the relationship between SMB and brightness temperature (or polarisation ratio of brightness temperatures) is not unequivocal, and b) that particular attention must be taken when studying the capability of satellite imagery to map SMB patterns in areas affected by surface melting. Arthern et al., 2006 already notice this potential issue but consider that regions where strong melting occurs represent only a small area fraction of Antarctica, mostly confined to peripheral ice shelves and overall have a small impact on the interpolated SMB distribution pattern. Here, we analyse in

Published by Copernicus Publications on behalf of the European Geosciences Union. 


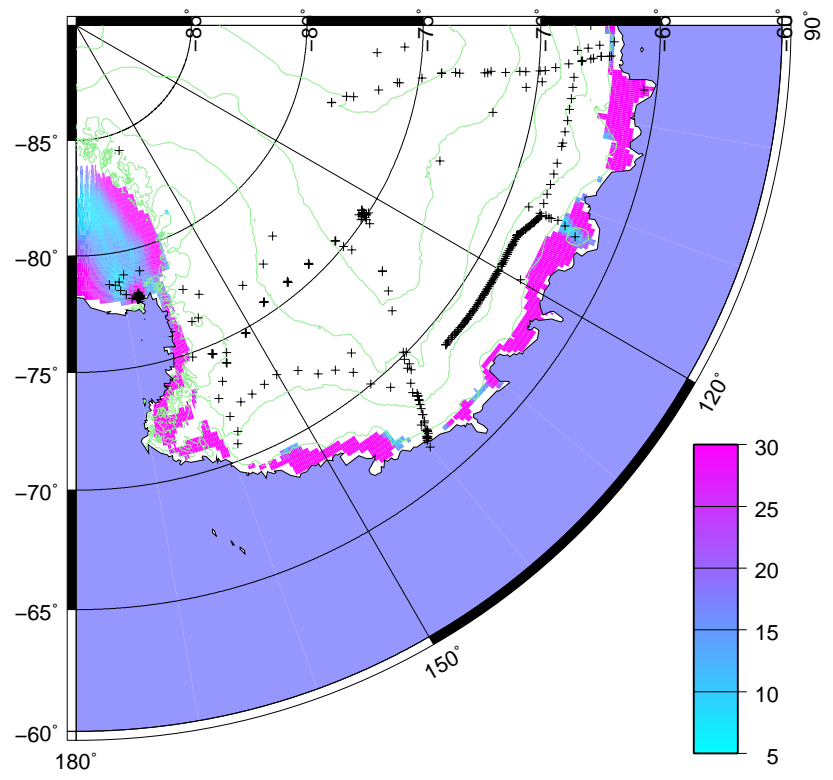

Fig. 1. Area of investigation with distribution pattern of surface melting areas observed in $90-180^{\circ}$ East Antarctica sector, from 1979 to 2006, by the SMMR (1979-1988) and SSM/I (1988onward) microwave radiometers. Crosses represent the filtered observed SMB data resulting from M07. Melting areas are expressed in average melting days by year.

more detail the effect of melting on the SMB retrieval and show that even moderate or rare melting, covering a significant surface of the Antarctic, degrades the retrieval.

In this paper, we concentrate in the $90^{\circ}-180^{\circ} \mathrm{E}$ sector. Quality-controlled and updated SMB observations (referred as M07) (Magand et al., 2007) confirm the good accuracy of A06's map in ever-dry-snow region as on the Antarctic Plateau (Sect. 3.1) but also show the negative impact of surface melting (Sect. 3.2). With physical arguments and by using a physical microwave emission model (Sect. 4) we explain and evaluate quantitatively the effect of surface melting on the polarisation ratio. Section 5 gives conclusions and recommendations.

\section{Data and methods}

\subsection{Selection of observed SMB data in $90^{\circ}-180^{\circ}$ E sector}

Recently, (Magand et al., 2007) produced a qualitycontrolled dataset of SMB measurements by discarding SMB measurements which do not fit quality criteria based on 1) an up-to-date review and quality rating of various SMB measurement methods and 2) coherency, completion, or lack of meta-information (location, date of measurement, time period covered by the SMB values, primary data sources) related to each SMB record. The filtering procedure was applied on V99's dataset (the same data are also in A06) in
Table 1. Mean relative differences $( \pm 1 \sigma)$ between various interpolated A06 SMB data set at M07 site measurements. Different interpolation methods are Nearest Grid Point (A06-NGP) and average of values within a radius of 20 (A06-20), 50 (A06-50) and $100 \mathrm{~km}$ (A06-100). In parenthesis, the maximum relative difference value.

\begin{tabular}{cccc}
\hline & A06-20 km & A06-50 km & A06-100 km \\
\hline A06-NGP & $2 \pm 2 \%(15 \%)$ & $3 \pm 4 \%(32 \%)$ & $5 \pm 6 \%(63 \%)$ \\
A06-20 km & - & $2 \pm 3 \%(19 \%)$ & $4 \pm 5 \%(47 \%)$ \\
A06-50 km & & - & $3 \pm 2 \%(24 \%)$ \\
\hline
\end{tabular}

the $90^{\circ}-180^{\circ} \mathrm{E}$ Antarctic sector, from Queen Mary to Victoria Lands (Fig. 1). New SMB measurements from the Australian, Russian and Italian-French scientific activities since 1998 (see references in Magand et al., 2007) have been added and provide independent ground-truth as they were not used by A06. A high quality dataset is thus obtained at the cost of a strong reduction in observation number and spatial coverage. In the present work, A06's interpolated SMB data are compared to our quality controlled dataset.

\subsection{Comparison method}

Each M07 measurement (corresponding to a field point) is compared to the nearest A06 grid-point (NearestGP) value, as well as to the average of A06's SMB values within a radius of 20,50 and $100 \mathrm{~km}$ to prevent representativeness misinterpretation.

Relative differences are calculated as follows:

Rel.Diff. $=\left(\frac{\overline{{\mathrm{A} 06_{i}-\mathrm{A}_{0} 6_{j}}}}{\mathrm{~A} 06_{i}}\right) \times 100$

with $\mathrm{A} 06_{i}, j$, the interpolated A06's SMB value at resolution $i$ and $j$, and associated to each observed SMB data. Table 1 shows relative differences between different methods are small.

The highest disagreement (mean value of $5 \pm 6 \%$ ) is observed between the nearest grid-point method and the average within $100 \mathrm{~km}$ (A06-100). Since the difference is small, only the average values within $100 \mathrm{~km}$ are presented in the next sections. Other dataset (NearestGP, $20 \mathrm{~km}, 50 \mathrm{~km}$ ) were also used but no major differences were found and conclusions are the same.

\section{Results}

\subsection{A06-100 SMB versus M07 SMB}

Comparisons between M07 SMB observations and the A06 map average at $100 \mathrm{~km}$ resolution (A06-100) are given in Fig. 2 and Table 2. In Fig. 2, black crosses mark the new measurements not used in A06. The overall correspondence 
Table 2. Comparison between A06-100's interpolated SMB data and different selections of corresponding observed SMB data (M07).

a "Outliers" are discarded from the present statistics.

${ }^{b}$ PF represent SMB data localized in areas characterized by Percolation Facies regions. RMS differences are expressed in kg $\mathrm{m}^{-2} \mathrm{yr}^{-1}$ (i.e. $\mathrm{mm} \mathrm{WE}$ ), and relative RMS are normalized by the A06-100 interpolated values.

\begin{tabular}{lccccc}
\hline & M07 (V99) & M07 (new) & M07 (all) & M07 in PF areas & M07 minus PF $^{\mathrm{a}}$ \\
\hline RMS difference $\left(\mathrm{kg} \mathrm{m}^{-2} \mathrm{yr}^{-1}\right)$ & 85 & 58 & 77 & 126 & 61 \\
Relative RMS difference (\%) & 31 & 46 & 35 & 51 & 28 \\
n data & 189 & 92 & 281 & 52 & 229 \\
\hline
\end{tabular}

is good, demonstrating the quality of the A06's SMB map in the studied sector. Larger scatter is found for the highest accumulation rates, usually in coastal areas. At a first glance, this is not surprising because of the low spatial sampling density in the latter areas characterized by high natural variability of the net accumulation.

Most points fit in the range of normally distributed yresiduals from the regression line. Only two points (not shown in the figure) are clearly outside the main cloud of points. These outliers come from an area between the Law Dome saddle $\left(67^{\circ} 15^{\prime} \mathrm{S}, 112^{\circ} \mathrm{E}\right)$ at $800 \mathrm{~m}$ a.s.l. and $\mathrm{A} 028$ $\left(68^{\circ} 24^{\prime} \mathrm{S}, 112^{\circ} \mathrm{E}\right)$ at $1650 \mathrm{~m}$ a.s.l. (Goodwin, 1988). Measured SMB is twice higher (781 and $\left.806 \mathrm{~kg} \mathrm{~m}^{-2} \mathrm{yr}^{-1}\right)$ than in A06's map (361 and $402 \mathrm{~kg} \mathrm{~m}^{-2} \mathrm{yr}^{-1}$, respectively). This is not surprising since the Law Dome region is characterized by strong precipitation, and SMB gradients due to the topography (Goodwin, 199; Goodwin et al., 2003). The typical length scale of elevation and spatial SMB variability is about $10 \mathrm{~km}$ (Van de Berg et al., 2006). The present-day SMB at Law Dome is marked by a very sharp east-west gradient; high accumulation on the east side is the result of dominant cyclonic flow from the south-east and the orographic effect of the dome (Van Ommen et al., 2004). Due to the large SMB gradients occurring in such small area, the $100 \mathrm{~km}$ resolution A06's SMB map may hardly be consistent with the local SMB observations. These two outliers are then discarded from our analysis and in particular the statistics (Table 2).

First column in Table 2 shows comparison between A06100 and filtered V99 SMB data (i.e. a quality-controlled subset of data available to and used by A06). Relative RMS difference $(31 \%)$ is in agreement with the error estimated by A06. Comparison with the new measurements (not used by A06) shows a larger RMS difference (46\%; Table 2, column 2). Statistics for M07 (new data+V99) (Table 2, column 3) only slightly deteriorates the correlation with RMS difference of $35 \%$ instead of $31 \%$.

Looking at the altitudinal distribution of all SMB data from the coast to $4000 \mathrm{~m}$ a.s.1., we observe that:

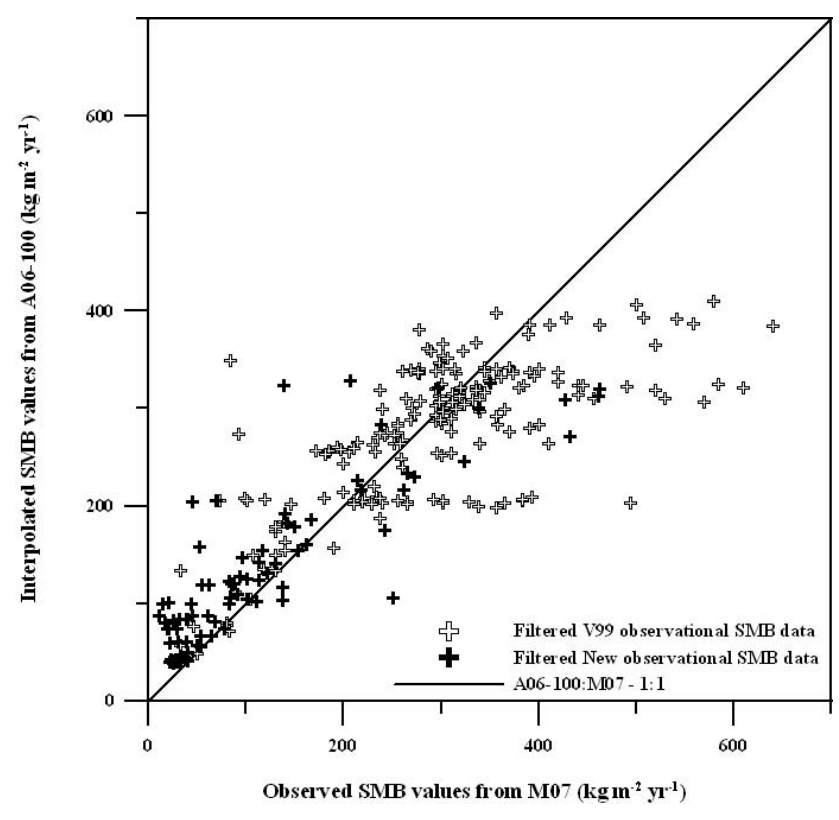

Fig. 2. Comparison between observed SMB values from filtered observed SMB data set (M07) to interpolated SMB values averaged at $100 \mathrm{~km}$ resolution (A06-100). Empty crosses correspond to observed SMB data used by V99 and A06, and black crosses represent new observed SMB data obtained from ITASE, RAE and ANARE projects since 1998 (see M07).

- New data are predominantly from the Antarctic plateau, above $2000 \mathrm{~m}$ a.s.1;

- A06's map tends to over-estimate observed SMB values on the Antarctic plateau, and under-estimate those below $2000 \mathrm{~m}$ a.s.1..

- From the coast to $1000 \mathrm{~m}$ a.s.1., large errors (RMS difference of $55 \%$ and $59 \%$, respectively in 0-500 $\mathrm{m}$ and 500-1000 m elevation bins) occur between the M07 and the A06-100 SMB data sets. Most of them are located in areas where surface melting events occur (i.e. melt areas). 


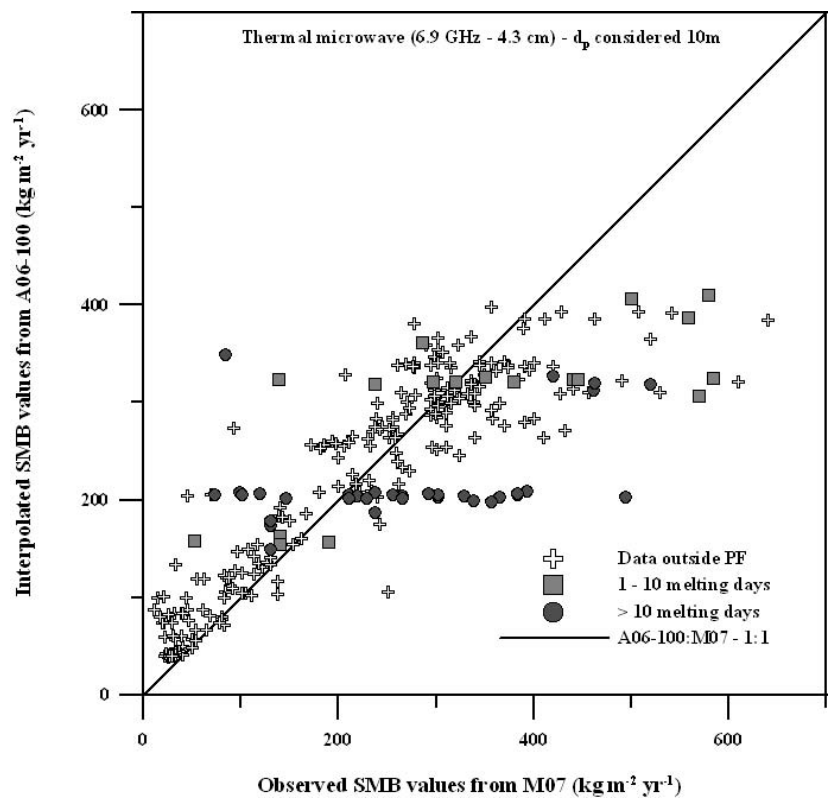

Fig. 3. Comparison between observed SMB values from filtered observational SMB data sets (M07) to interpolated SMB values averaged in $100 \mathrm{~km}$ resolution (A06-100) with distribution pattern of observed SMB points located in $P$ ercolation $F$ acies $(P F \sim$ melting events) areas. Cumulative melting days are calculated on the basis of $6.9 \mathrm{GHz}$ microwave penetration depth $\left(d_{p}\right)$ of $10 \mathrm{~m}$ in snow pack. SMB values are expressed in $\mathrm{kg} \mathrm{m}^{-2} \mathrm{yr}^{-1}$ (i.e. $\mathrm{mm}$ W.E.).

\subsection{Snow melting areas and microwave signature}

The presence of liquid water in snow induces a large increase of the emissivity and radical shortening of the penetration depth (Rott and Sturm, 1991) with respect to dry snow. This singular signature makes surface melting easily detectable by passive microwave remote sensing. Using 19 $\mathrm{GHz}$ horizontally polarised brightness temperature acquired by the SMMR (1979-1988) and SSM/I (1988-onward) microwave radiometers, melt events are mapped every day (or every other day for SMMR) in Antarctica at about $50 \mathrm{~km}$ effective resolution (Torinesi et al., 2003; Picard and Fily, 2006). It is worth noting at this point that

- The dataset of melt events is independent of the microwave observations used by A06 to produce the SMB map. Different microwave frequencies and time periods are used (events detection uses daily data while the polarization ratio is based on many years average).

- The technique does not provide information about the amount of melted water during the event nor about the processes that occurs during and after the melt event (percolation, refreezing and so on) (but an improved method has been proposed recently for the Greenland Ice Sheet - Winebrenner et al., 2001). It is difficult to assess what happens during refreezing and whether

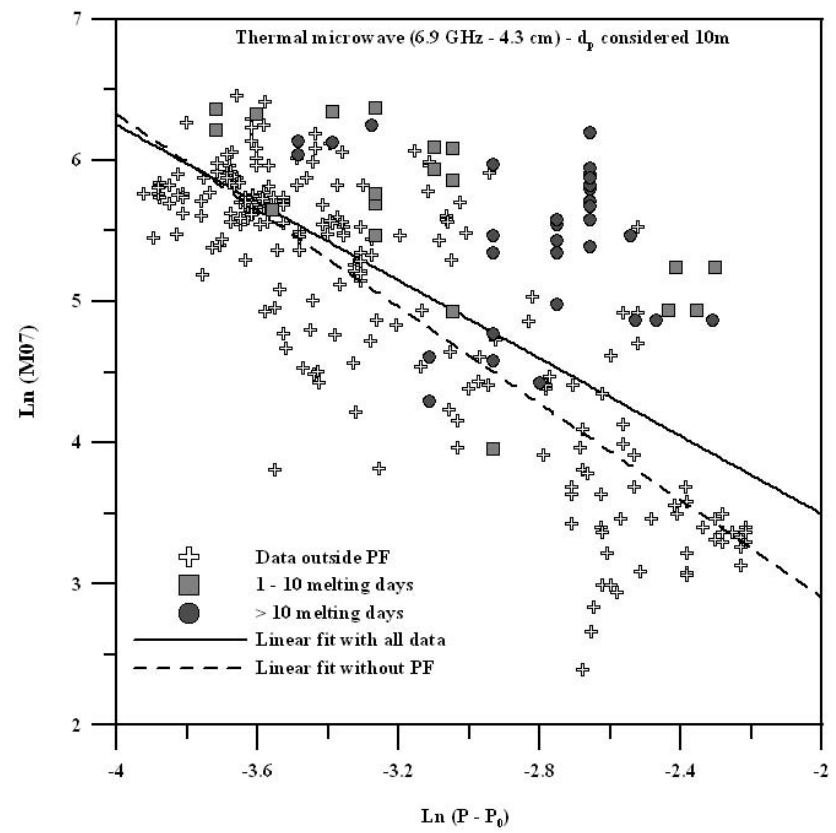

Fig. 4. Comparison between the logarithmically transformed Polarisation ratios issued from 2002-2006 satellite record and the M07 SMB values. Polarisation ratio is expressed as $P$ minus component $P_{0}$; this last component of polarization being issued from reflection at the air-snow interface as thermal emission leaves the snow. Observed SMB data located in Percolation $F$ acies areas are reported. Cumulative melting days are calculated on the basis of $6.9 \mathrm{GHz}$ microwave penetration depth $\left(d_{p}\right)$ of $10 \mathrm{~m}$ in snow pack.

a dense or ice layer is formed. As a consequence, the number of melt events is only a rough proxy for the number of ice layers.

The number of ice layers that could affect the polarisation ratio at $6.9 \mathrm{Ghz}$ depends on the number of melt events that have occurred in the past, the microwave penetration depth and the accumulation which governs burial of ice layers. At 6.9 $\mathrm{GHz}$, observed brightness temperature results from the emission in the upper tens of meters (Surdyk, 1995; Surdyk, 2002). Penetration depth at $5.3 \mathrm{GHz}$ is also estimated of the order of tens of meters in dry polar firn (Partington, 1998; Bingham and Drinkwater, 2000). Depending on the annual $\mathrm{SMB}$, dense layers in the first tens of meters have formed a few years up to decades ago. To estimate the number of melt layers in the 10 first meters, we computed the total number of melting days during the period required for accumulating such quantities of snow. A mean snow density of $500 \mathrm{~kg} \mathrm{~m}^{-3}$ is assumed.

M07 SMB data issued from areas submitted to melting events from 1979 to 2006 are presented in Figs. 3 and 4 as grey squares (1-10 melting days) and black circles (more than 10 melting days). Figure 3 shows that a large number of the observed SMB which do not match well with A06-100's SMB comes from regions affected by surface melting. Points 
from the wet-zone are clearly divided in two groups depending on the number of melting days (Fig. 3). The horizontal alignment for each group shows the absence of relationship between A06-100 SMB and the field observations. This results in a larger RMS difference (51\% instead of $34 \%$ with all data, Table 2, column 4). The RMS difference is even larger $(56 \%)$ if only points affected by more than 10 melting days are considered.

\section{Discussion}

From Table 2 it is clear that excluding SMB data from melt zones clearly improves the fit between A06 map and the observations with RMS relative difference of $28 \%$ instead of $35 \%$. We further investigate here the physical origin of this result. The polarisation ratio is sensitive to the number of layers and density contrast between these layers. Large polarisation ratio corresponds to strong stratification. Any change of density in the snowpack as well as the top air-snow interface are seen by microwaves as a change in refractive index. At observation angles around $50^{\circ}-53^{\circ}$ close to the Brewster angle, every interface preferentially transmits vertically polarized waves and, equivalently, preferentially reflects horizontally polarized waves (West et al., 1996). The microwaves emitted by thermal agitation in the deep layers of the snow pack must cross many interfaces before escaping from the snow pack and reaching the satellite. Since the transmission at each interface is larger for the vertically-polarized wave, the brightness temperature at vertical polarisation is larger than the horizontally one, and the difference between both polarisations increases with the number of layers and density contrast. The polarisation ratio $P-P_{0}$ is then proportional to the layer number within the snow-pack, where $P_{0}=0.035$ is the polarisation ratio due to the air-snow interface (Arthern et al., 2006):

$P=\frac{T_{B}(V)-T_{B}(H)}{T_{B}(V)+T_{B}(H)}$

The link between number of layers and accumulation is less clear. Winebrenner et al., 2001 related the variation in polarisation ratios (modelling and in situ observations) to the accumulation occurring at different observation points in Greenland dry snow region. They showed a strong link between random firn density contrast variations and the SMB. Arthern et al., 2006 extended this approach by accounting for a temperature dependence on the stratification kinetic in Antarctica (layers form slower at lower temperature). Further investigations are needed to understand the link between accumulation and stratification but from a pragmatic point of view, a clear relationship exists and allows accurate SMB estimation in dry zones.

In the melt areas, the polarisation ratio is not so clearly related to the accumulation. Figure 4 shows $\operatorname{Ln}\left(P-P_{0}\right)$ as a function of $\operatorname{Ln}(\mathrm{M} 07 \mathrm{SMB})$. Similarly to A06, brightness temperature $\left(T_{b}\right)$ at $6.9 \mathrm{Ghz}$ acquired by the Advanced Microwave Scanning Radiometer (ASMR-E) on Aqua satellite (Cavalieri, 2004) are averaged between 2002 and 2006 and used to estimate the polarisation ratio $P-P_{0}$. The overall correlation is significantly different from zero at the $99 \%$ level ( $n=278 ; R=0.708 ; p<0.01)$. However, distinguishing points between dry and melt zones shows a) that most of the points located in melt zones are characterized by higher polarisation ratio than those with similar SMB in the dry zones and b) there is no clear dependence between the SMB values in melt zones and the polarisation ratio. The SMB thus cannot be directly correlated to the polarisation ratio. By eliminating points affected by melting, the relationship between polarisation ratio and SMB is stronger $(n=227 ; R=0,850$; $p<0.01)$.

Using the Microwave Emission Model of Layered Snow packs (Wiesmann and Mätzler, 1999), we have simulated the polarisation ratio $P-P_{o}$ for a variety of structured snow packs. We found that a snow pack composed of snow layers (fine grain, density $400 \mathrm{~kg} \mathrm{~m}^{-3}$ ) interleaved with 3 -cm thick ice layers (density $700 \mathrm{~kg} \mathrm{~m}^{-3}$ ) regularly spaced every $2 \mathrm{~m}$ has a polarisation ratio of $\operatorname{Ln}\left(P-P_{o}\right)=-2.0$, the upper bound of those observed in Fig. 4 for the pixels in the melt areas. A single melt event every 2 years is sufficient for creating such a structure assuming 1-m annual accumulation. More ice layers or weaker accumulation would lead to larger polarisation ratio. These results show that even infrequent melt events result in polarisation ratios larger than the typical range of polarisation used to retrieve SMB. It means that even infrequent melting disrupts significantly the relationship between $P-P_{o}$ and SMB.

To build the background field model capturing the spatial variability in SMB, A06 used 46 observations that are located in areas affected by melting (in the sector $90-180^{\circ}$ East where melting is relatively infrequent). The results presented in this paper strongly suggest the background model is inaccurate in the melt areas even if the background model also uses other information (i.e. thermal infrared). How this inaccuracy translates into the A06 map is difficult to quantify as the SMB measurements are the primary source of information to build the map and the background model is only used for the interpolation. However, the main effect seems to be an under-estimation of the SMB in the melt areas. This may be explained by the fact that ice layers tend to increase the polarisation ratio and thus to decrease the SMB estimation. Van de Berg et al. (2004) also noticed that in the coastal regions, Vaughan et al. (1999)'s microwave based map is under-estimated with respect to SMB predicted by a calibrated regional climate model. However, this is only partially supported in Fig. 3 which shows that not all the points affected by surface melting are below the 1:1 line. In any cases, we recommend polarisation ratios should not be used in melt areas to infer the SMB. 


\section{Conclusions}

Comparing the recent A06's Antarctic SMB map with quality-controlled in-situ observations in the $90^{\circ}-180^{\circ}$ East Antarctic sector (Magand et al., 2007), we show that, in spite of a fair overall agreement on the plateau, there is a poor agreement in the coastal regions affected by surface melting, even infrequent. The disagreement in melt areas is a consequence of the fact that melt-refreeze layers affect the microwave emissivity in horizontal polarisation more strongly than accumulation does. In some other places, the polarisation ratio may even be unrelated to the SMB. This includes the blue ice area (Bintaja, 1999; Winther et al., 2001) where no snowpack layering is present, and the megadune areas. The morphology of megadunes is complex (Frezzotti et al., 2002) but the snowpack seems to be weakly structured as revealed by the lower polarisation ratio (around 0.05 in the megadune field South of Dome C) than in the surrounding (around 0.07) or on the ice divide (around 0.09). Since a low polarisation ratio is interpreted as an high accumulation, it is not surprising that A06 map shows larger accumulation in the megadune field South of Dome $\mathrm{C}$ than around although the accumulation is probably lower there (Courville et al., 2007). Further statistical analysis is however difficult given the lack of in situ SMB measurements in these areas.

Surface melting in the $90-180^{\circ} \mathrm{E}$ sector in East Antarctica observed by microwave radiometers (Picard and Fily, 2006) represents more than $0.6 \times 10^{6} \mathrm{~km}^{2}$ i.e. approximately $14 \%$ of the sector $\left(\sim 4.4 \times 10^{6} \mathrm{~km}^{2}\right)$. Because the mean SMB is comparatively higher in the coastal zones, the mean SMB in the melt areas is $\sim 24 \%$ of total SMB in the sector. Extrapolating to the whole of Antarctica, melt areas represent $\sim 25 \%$ of the total surface and about $42 \%$ of the total SMB. Areas affected by surface melting are then far from negligible in terms of surface area and even less so in terms of accumulation volume. Thus, while A06 provides the latest and most up-to-date evaluation of the spatial distribution of SMB over Antarctica, along with an original and useful evaluation of errors, it is expected that not using microwave observations in melt areas for building the background model could further increase the accuracy of the map.

Acknowledgements. In Wilkes and Victoria Land sectors, most of observed Surface Mass Balance data were obtained from recent research carried out in the framework of the Italian PNRA in collaboration with ENEA Roma, and supported by the French Polar Institute (IPEV). The authors are grateful to all colleagues who participated in field work and sampling operations and those whose comments and editing helped to improve the manuscript.

Edited by: M. Van den Broeke

\section{References}

Arthern, R. J., Winebrenner, D. P., and Vaughan, D. G.: Antarctic snow accumulation mapped using polarisation of $4.3 \mathrm{~cm}$ wavelength microwave emission, J. Geophys. Res., 111, D06107, doi:10.1029/2004JD005667, 2006.

Bingham, A. W. and Drinkwater, M.: Recent changes in the microwave scattering properties of the Antarctic ice sheet, IEEE Transactions on Geoscience and Remote Sensing, 38, 18101820, 2000.

Cavalieri, D. and Comiso, J.: AMSR-E/Aqua daily L3 $25 \mathrm{~km} \mathrm{~Tb}$, sea ice temperature and sea ice conc, polar grids V001, January to December 2003., Natl. Snow and Ice Data Cent., Boulder, Colorado, 2004.

Drinkwater, M. R., Long, D. G., and Bingham, A. W.: Greenland snow accumulation estimates from satellite radar scatterometer data, J. Geophys. Res., 106(D24), 33 935-33 950, 2001.

Forster, R., Jezek, K. C., Bolzan, J., Baumgartner, F., and Gogineni, P.: Relationships between radar backscatter and accumulation rates on the Greenland ice sheet, Int. J. Remote Sens., 20, 3131-3147, 1999.

Genthon, C. and Krinner, G.: Antarctic surface mass balance and systematic biases in general circulation models, J. Geophys. Res., 106, 20 653-20 664, 2001.

Goodwin, I. D.: Ice sheet topography and surface characteristics in Eastern Wilkes Land, East Antarctica, ANARE Research Notes, 64, 100 pp., 1988.

Goodwin, I. D.: Snow accumulation variability from seasonal surface observations and firn-core stratigraphy, Eastern Wilkes Land, Antarctica, J. Glaciol., 37, 383-387, 1991.

Goodwin, I. D., De Angelis, M., Pook, M., and Young, N. W.: Snow accumulation variability in Wilkes Land, East Antarctica, and the relationship to atmospheric ridging in the $130^{\circ}-170^{\circ} \mathrm{E}$ region since 1930, J. Geophys. Res., 108, 4673-4689, 2003.

Magand, O., Genthon, C., Fily, M., Krinner, G., Picard, G., Frezzotti, M., and Ekaykin, A. A.: An up-to-date quality-controlled surface mass balance data set for the $90^{\circ}-180^{\circ} \mathrm{E}$ Antarctica sector and 1950-2005 period, J. Geophys. Res., 112, D12106, doi:10.1029/2006JD007691, 2007.

Munk, J., Jezek, K. C., Forster, R., and Gogineni, P.: An accumulation map for the Greenland dry-snow facies derived from spaceborne radar, J. Geophys. Res., 108(D09), 4280, doi:10.1029/2002JD002481, ACL 8 1-12, 2003.

Partington, K. C.: Discrimination of glacier facies using multitemporal SAR data, J. Glaciol., 44, 42-53, 1998.

Picard, G. and Fily, M.: Surface melting observations in Antarctica by microwave radiometers: Correcting 26-year time series from changes in acquisition hours, Remote Sens. Environ., 104, 325336, doi:10.1016/j.rse.2006.05.010, 2006.

Rott, H. and Sturm, K.: Microwave signature measurements of Antarctic and Alpine snow, In 11th EARSeL symposium, Graz, Austria, 140-151, 1991.

Surdyk, S.: Using microwave brightness temperature to detect short-term surface air temperature changes in Antarctica: An analytical approach, Remote Sens. Environ., 80, 256-271, 2002.

Surdyk, S. and Fily, M.: Results of a stratified snow emissivity model based on the wave approach: Application to the Antarctic ice sheet, J. Geophys. Res., 100, 8837-8848, 1995.

Torinesi, O., Fily, M., and Genthon, C.: Variability and trends of summer melt period of Antarctic ice margins since 1980 from 
microwave sensors., J. Clim., 16, 1047-1060, 2003.

Van de Berg, W. J., Van den Broeke, M. R., Reijmer, C. H., and Van Meijgaard, E.: Reassessment of the Antarctic surface mass balance using calibrated output of a regional atmospheric climate model, J. Geophys. Res., 111, D11104, doi:10.1029/2005JD006495, 2006.

Van den Broeke, M., Jan Van de Berg, W., Van Meijgaard, E., and Reijmer, C.: Identification of Antarctic ablation areas using a regional atmospheric climate model, J. Geophys. Res., 111, D18110, doi:10.1029/2006JD007127, 2006.

Vaughan, D. V., Bamber, J. L., Giovinetto, M., Russell, J., and Cooper, A. P. R.: Reassessment of Net Surface Mass Balance in Antarctica, J. Clim., 12, 933-946, 1999.
West, R. D., Winebrenner, D. P., Tsang, L., and Rott, H.: Microwave emission from density-stratified Antarctic firn at $6 \mathrm{~cm}$ wavelength, Journal of Glaciology, 42, 63-76, 1996.

Wiesmann, A. and Mätzler, C.: Microwave Emission Model of Layered Snowpacks, Remote Sens. Environ., 70(3), 308-316, 1999.

Winebrenner, D. P., Arthern, R. J., and Shuman, C. A.: Mapping Greenland accumulation rates using observations of thermal emission at $4.5 \mathrm{~cm}$ wavelength, J. Geophys. Res., 106, 33919 $33934,2001$. 